\title{
Pengalaman Belajar Anak: Mengukur Tingkat Prestasi Siswa Sekolah Dasar yang Menempuh Pendidikan Taman Kanak-Kanak
}

\author{
Hermanto \\ PG-PAUD, Universitas Muhammadiyah Kendari \\ Email: hermanto.tembe@gmail.com
}

\begin{abstract}
ABSTRAK: Disepakati oleh para pakar bahwa pendidikan anak usia dini adalah entri awal pengalaman belajar seorang manusia pada pendidikan formal. Oleh karena itu, tujuan penelitian ini adalah mengukur tingkat prestasi belajar yang tidak memiliki pengalaman belajar di TK. Penelitian ini bersifat kualitatif deskriptif. Dilaksanakan di sekolah dasar (SD) kecamatan Mata Oleo Kabupaten Bombana, populasi dalam penelitian yaitu murid SD kecamatan Mataoleo dengan teknik sampling bertingkat (Memilih 5 SD yang ada di kecamatan Mataoleo). Sebanyak 66 murid SD dijadikan sampel. Berdasarkan hasil penelitian, disimpulkan bahwa murid SD yang tidak memiliki pengalaman belajar di Taman Kanak Kanak mempunyai prestasi cukup baik atau dibawa rata rata. Oleh karena itu, diharapkan sebelum anak masuk sekolah dasar harus memiliki melalui pengalaman belajar di taman kanak kanak.
\end{abstract}

Katakunci: Pendidikan Anak Usia Dini, Pengalaman Belajar, Prestasi Belajar, Sekolah Dasar.

\section{ABSTRACT:}

Experts believed that early childhood education was the first formal admission into formal education for a human being. Therefore, the goal of this research is to determine the degree of learning accomplishment of children who have never attended kindergarten. This study is descriptive in nature and qualitative. With multistorey sampling approaches, the study was implemented at elementary school (SD) Eata Oleo District Bombana, with the population in the study being a student of SD Matooleo Subdistrict (selecting 5 elementary schools in Matooleo sub-district). A total of 66 primary school children were chosen for the study. According to the findings of the study, primary school pupils who had no prior learning experience in kindergarten had a fairly excellent accomplishment on average. Hence, it is anticipated that a kid must have completed kindergarten before enrolling in primary school.

Keywords: Early childhood education, learning experience, learning achievement, elementary school.

\section{PENDAHULUAN}

Undang-Undang Nomor 20 Tahun 2003 tentang Sistem Pendidikan Nasional menyebutkan bahwa pendidikan adalah usaha sadar dan terencana untuk mewujudkan suasana belajar dan proses pembelajaran agar peserta didik/warga belajar secara aktif mengembangkan potensi dirinya untuk memiliki kekuatan spiritual keagamaan, pengendalian diri, kepribadian, kecerdasan, akhlak mulia, serta keterampilan yang diperlukan dirinya, keluarga dan masyarakat, bangsa dan negara (Hamid, Hidayat \& Safitri, 2021). Sedangkan pendidikan anak usia dini adalah suatu 
upaya pembinaan yang ditujukan kepada anak sejak lahir sampai dengan usia enam tahun yang dilakukan yang baik, untuk membantu pertumbuhan dan perkembangan jasmani dan rohani, sehingga anak memiliki kesiapan dalam memasuki pendidikan lebih lanjut.

Pendidikan pada hakikatnya adalah pemberian upaya untuk menstimulasi, membimbing, mengasuh, dan menyediakan menu kegiatan pembelajaran yang akan menghasilkan kemampuan dan keterampilan pada anak agar mereka siap menempuh jenjang pendidikan selanjutnya (Pahenra, 2021). Hal ini selaras dengan UndangUndang tentang Sistem Pendidikan Nasional Nomor 20 Tahun 2003 pasal 1 ayat (14) yang menyatakan bahwa pendidikan anak Usia Dini adalah suatu upaya pembinaan yang ditujukan kepada anak sejak lahir sampai dengan usia enam tahun yang dilakukan melalui pemberian stimulus pendidikan untuk membantu pertumbuhan dan perkembangan mental, fisik dan rohani agar anak memiliki kesiapan dalam memasuki pendidikan lebih lanjut.

Depdiknas yang dikutip Hibama, S. Rahman (2009: 88) bahwa pendidikan TK/RA merupakan upaya sadar untuk pemberian kegiatan stimuli yang terencana baik melalui program pembelajaran pendidikan bagi anak usia 4- 6 tahun dengan menu bahan-bahan ajar yang generik berupa dasar-dasar pengetahuan yang essensial melalui aktivitas bermain yang dititikberatkan pada peletakkan dasar ke arah pertumbuhan dan perkembangan fisik (koordinasi motorik kasar dan halus), kecerdasan (daya pikir, daya cipta, emosi dan spiritual), sosio emosional (sikap, perilaku, agama); bahasa; dan komunikasi; yang disesuaikan dengan keunikan, minat, bakat, dan tahap-tahap tumbuh-kembang yang dilalui oleh anak.

Merupakan suatu hal yang menarik untuk dikaji lebih lanjut pada daerah yang berbeda, dalam rangka pembuktian konsep tujuan pendidikan anak usia dini, yang hasilnya diharapkan dapat mendukung atau melengkapi kajian-kajian yang telah dilakukan beberapa peneliti sebelumnya. Oleh karena itu, penulis merasa termotivasi untuk melakukan hal tersebut di wilayah Kabupaten Bombana, pada sebagian besar SD di wilayah Kecamatan Mata Oleo Kabupaten Bombana.

Materi pembelajaran untuk murid kelas I tingkat SD, tidaklah berbeda jauh dengan yang diperoleh anak di TK bahkan dapat dikatakan serupa, hanya kedalaman materinya dan teknik atau metode penyajiannya saja yang berbeda. Untuk anak didik di TK/RA, sesuai aturan pada Permendiknas No. 58/2009 tentang Standar Pendidikan Anak Usia Dini lebih banyak dilakukan dalam bentuk permainan dengan benda-benda kongkrit yang menyenangkan bagi anak, sedangkan untuk murid SD nampak agak formal mengikuti aturan dengan acuan kurikulum di sekolah. Sementara itu, dari segi pendekatan penyajian materi yang digunakan pendidik, sesuai aturan Permendiknas No. 58/2009 (Depdiknas, 2012: 642), di TK menggunakan pendekatan tematik sama dengan yang dilakukan guru pada tingkat SD sesuai aturan pada Permendiknas No. 41/2007 tentang Standar Pendidikan Dasar dan Menengah (Depdiknas, 2012: 540).

Sehubungan dengan hal tersebut, bila dikaitkan dengan konsep dan tujuan pendidikan anak usia dini di lembaga PAUD/TK, yang intinya adalah mempersiapkan anak dengan berbagai pengalaman-pengalaman belajar sesuai aspek perkembangan anak agar memiliki kesiapan yang mantap dalam memasuki pendidikan lebih lanjut maka dapat dipahami bahwa ada suatu keterkaitan/hubungan yang nampak erat. Hal 
ini sebagaimana yang diungkapkan para ilmuwan psikologi pendidikan anak yang dikutip Gustian (2002) bahwa berdasarkan tinjauan psikologis, aspek-aspek fisik, mental-intelektual, emosi, dan aspek sosial setiap anak yang akan memasuki dunia sekolah dasar harus dipersiapkan sedini mungkin, sebab sukses tidaknya seorang anak dalam beradaptasi dan belajar pada dunia sekolah (SD), sangat ditentukan oleh persiapan-persiapan yang diberikan dan yang dimiliki anak untuk menghadapi dunia barunya itu. Tentunya, anak tidak mungkin mempersiapkan dirinya sendiri, karena itu peran aktif lembaga PAUD/TK (disamping orang tua di rumah) melalui programprogram belajar bagi anak usia dini adalah merupakan faktor yang sangat menentukan pula.

Namun, khususnya di Kabupaten Bombana, hal itu baru merupakan dugaan sementara, jika ingin diketahui taraf kebenarannya, maka masih harus dibuktikan melalui suatu pengkajian ilmiah dalam bentuk kegiatan penelitian. Terkait dengan prihal kegiatan penelitian, menurut Dwihastuti (2008: 100) bahwa keberhasilan pendidikan anak didik usia dini di lembaga PAUD/TK, menunjukkan taraf efektivitas keberhasilan penyelenggaraan pendidikan yang diupayakan lembaga PAUD itu, yang hal itu dapat diukur dari pencapaian prestasi akademik atau non-akademik dari anak yang merupakan lulusan lembaga PAUD/TK saat lulusannya itu berada pada jenjang pendidikan SD atau yang sederajat, dengan melakukan perbandingan-perbandingan atau melakukan kegiatan pembuktian pendekatan uji statistik melalui teknik uji beda.

Berdasarkan uraian latar belakang yang dipaparkan di atas, maka penulis berkehendak melakukan suatu penelitian dengan pendekatan statistik nonparametrik untuk menganalisis dan membuktikan kebenaran hipotesis tentang ada tidaknya suatu perbedaan nilai tingkat prestasi belajar antara murid Kelas I yang memiliki pengalaman belajar dengan yang tidak memiliki pengalaman belajar program TK pada Sekolah Dasar (SD) di Wilayah Kecamatan Mata Oleo Kabupatena Bombana.

Bertolak dari uraian pendahuluan di atas, maka rumusan pertanyaan pada penelitian ini adalah: Bagaimanakah deskripsi prestasi belajar yang memiliki pengalaman belajar program Taman kanak Kanak pada murid Kelas 1 SD Negeri di Kecamatan Mataoleo Kabupaten Bombana? Tujuan penelitian untuk mengetahui perbedaan prestasi belajar yang memiliki pengalaman belajar program Taman kanak Kanak pada murid Kelas 1 Sekolah Dasar Negeri di Kecamatan Mataoleo Kabupaten Bombana.

\section{METODE PENELITIAN}

Jenis penelitian ini adalah penelelitian kualitatif deskritip. Penelitian ini dilakukan pada bulan Oktober tahun 2019 hingga Pebruari 2020 . Lokasi pengambilan data yang dimaksud bertempat pada 5 (lima) SD yang berada di wilayah Kecamatan Mata Oleo Kabupaten Bombana. Populasi penelitian adalah semua murid kelas 1 SD di kecamatan Mata Oleo kabupaten Bombana. Dari jumlah tersebut diambil sampel berdasarkan purposive random sampling sebanyak 66 murid yang terbagi ke 5 sekolah dasar yang ada di kecamatan Mataoleo Kabupaten Bombana. 
Tabel 1 Distribusi Sampel Populasi pada Lima Sekolah Dasar di Kecamatan Mata Oleo

\begin{tabular}{|l|c|c|}
\hline \multicolumn{1}{|c|}{ Sekolah Dasar } & Jumlah Murid Kls I & Jumlah Murid non Program TK \\
\hline SDN 36 Tambako & $\mathbf{3 9}$ & $\mathbf{2 3}$ \\
\hline SDN 37 Mata Oleo & $\mathbf{3 9}$ & $\mathbf{2 2}$ \\
\hline SDN Toli-Toli & $\mathbf{1 7}$ & $\mathbf{1 2}$ \\
\hline SDS Mawar & $\mathbf{1 2}$ & $\mathbf{5}$ \\
\hline SDN Batu Sampe & $\mathbf{1 1}$ & $\mathbf{4}$ \\
\hline Jumlah Total & 118 & 66 \\
\hline
\end{tabular}

Sumber: Sekolah Dasar di Wilayah Kecamatan Mata Oleo, Tahun 2019

Untuk mendapatkan data-data yang diperlukan pada penelitian, peneliti menggunakan teknik dokumentasi dengan mengumpulkan data hasil penilaian guru. Teknik dokumentasi dilakukan peneliti untuk mengumpulkan dokumen-dokumen menyangkut data-data latar belakang variabel atribut setiap subjek (murid lulusan TK dan murid yang bukan dari lulusan TK) pada seluruh populasi terjangkau murid kelas I SD di Kecamatan Mataoleo. Sedangkan data nilai tingkat prestasi belajar, dilakukan dengan mengumpulkan dokumen data hasil penilaian pada akhir semester yang telah dilakukan guru sebelumnya. Data-Data nilai prestasi belajar yang dikumpulkan itu, hanya terbatas pada nilai prestasi belajar dari murid kelas I yang menjadi subjek pada penelitian ini yang datanya telah tertuang pada rapor masing-masing murid yang merupakan hasil penilaian yang dilakukan guru. Data-data prestasi belajar itu, merupakan data kontinum yang berskala ordinal, karena merupakan hasil olahan guru dari akumulasi beberapa nilai hasil-hasil belajar yang diperoleh murid untuk nilai akhir pada akhir semester.

Kegiatan menganalisis data-data yang telah diperoleh dari hasil penelitian ini nantinya, dilakukan teknik analisis statistik deskriptif yaitu sebagaimana yang dilakukan pada penelitian ini, adalah usaha peneliti dalam memberi jawaban atas permasalahan yang diajukan pada penelitian ini, yang masing-masing hanya berkenan dengan satu variable saja dan tidak menghubungkannya dengan variable lain (Riduwan, 2011: 164)

Mencermati makna uraian tersebut, maka kegiatan analisis secara deskriptif pada penelitian ini, dilakukan untuk mendeskripsikan keadaan data variable yang dimaksud yakni gambaran tingkat prestasi belajar perolehan murid SD kelas I yang tidak memiliki pengalaman belajar program TK sebelum masuk SD, di Kec. Mata Oleo Bombana.

Untuk maksud memberikan deskripsi keadaan pada masing-masing variable sebagaimana yang dimaksud di atas, terlebih dahulu dilakukan penganalisisan datadata sampel (statistik) yang diperoleh dengan jalan menentukan nilai rata-rata/mean, derajat deviasi, dan standar deviasi dari data nilai-nilai prestasi belajar perolehan pada masing-masing kelompok sampel populasi murid. Selanjutnya menyesuaikan nilai-nilai data hasil perhitungan tersebut dalam bentuk kategorisasi kedudukan nilai rata-rata prestasi belajar sesuai hasil yang diperoleh masing-masing kelompok sampel yang diteliti pada penelitian ini. Adapun, deskripsi kategorisasi dari nilai prestasi belajar yang diterapkan, didasarkan pada hasil analisis Mean dan standar deviasi dari sekumpulan data yang diperoleh pada setiap kelompok sampel, dengan mengacu pada 
Tabel 2 Urutan kedudukan Atas Lima Rangking (Sudijono, 2009)

\begin{tabular}{|c|c|}
\hline Batasan Standar Interval Nilai Prestasi & Deskripsi Kategori Tingkat Prestasi \\
\hline Nilai $>$ Mean + 1.5 SD & Sangat Baik \\
\hline Mean + 1.5SD > Nilai < Mean + 0.5 SD & Baik \\
\hline Mean + 0.5SD > Nilai < Mean - 0.5 SD & Kurang Baik \\
\hline Mean - 0.5SD > Nilai < Mean - 1.5 SD & Sangat Kurang Baik \\
\hline Nilai < Mean - 1.5 SD &
\end{tabular}

Setelah semua data-data nilai disesuaikan dengan kriteria kategorisasi di atas, maka selanjutnya dilakukan analisis deskriptif persentase berdasarkan kategorisasinya pada kedua kelompok sampel menggunakan teknik perhitungan dengan rumus berikut:

$$
\%=\frac{\sum \text { unit data yang berkategori sama }}{\text { Lunit data seluruhnya }} \times 100 \%
$$

Dari hasil analisis yang diperoleh dengan rumus di atas, peneliti menggambarkan data hasilnya dalam bentuk distribusi frekuensi persentatifnya lalu melakukan interpretasi. Menurut Irianto (2010: 7), distribusi akan memberikan deskripsi informasi jelas tentang posisi masing-masing bagian secara persentatif dalam keseluruhan (seluruh data-data kategorisasi nilai pada kedua kelompok sampel), karena telah dapat dilihat adanya suatu gejala perbedaan antara kelompok yang satu dengan kelompok lainnya atau kelompok skor nilai sampel yang akan peneliti perbandingkan dalam penelitian.

\section{HASIL PENELITIAN DAN PEMBAHASAN Hasil Penelitian}

Data-data olahan hasil dari variabel prestasi murid yang tidak memiliki pengalaman belajar di tamana kanak kanak yang didesripsikan meliputi: nilai prestasi total seluruh sampel murid, nilai rata-rata, nilai data maksimal, nilai data minimal, nilai standar deviasi, dan distribusi frekuensi relatif. Distribusi frekuensi relatif, didasarkan pada jumlah kategori nilai tingkat prestasi belajar dari seluruh sampel murid yang mengacu pada nilai Mean dan standar deviasi sebaran keseluruan data nilai prestasi sesuai urutan kedudukan atas lima rank jenjang kategori tingkatan prestasi belajar.

Berdasarkan hasil pengumpulan data diperoleh kumpulan data mentah berupa nilai prestasi belajar akhir semester ganjil dari prestasi murid yang tidak memiliki pengalaman belajar di tamana kanak kanak yang tersebar pada 5 (lima) SD Kecamatan Mata Oleo Kab.Bombana. Dari hasil analisis deskriptif pengolahan data mentah tersebut diperoleh hasil berupa data nilai maksimum atau nilai tertinggi tingkat prestasi belajar perolehan seluruh sampel murid dari dua kelompok populasi murid kelas I yang bersekolah pada 5 (lima) SD se-Kec.Mata Oleo Kab. Bombana. Secara keseluruhan sejumlah 66 sampel murid, kisaran nilai maksimum atau nilai tertinggi tingkat prestasi belajar murid adalah sebesar 80.66; sedangkan kisaran nilai prestasi minimum atau nilai terendah dari seluruh murid adalah bernilai 50.00; Sedangkan 
secara rata-rata, diperoleh hasil kisaran nilai rata-rata prestasi belajar dari seluruh 66 murid itu berkisar $=62.36$.

Tabel 3 Deskripsi Gabungan Seluruh Sebaran Data Nilai Prestasi Belajar Murid yang Tidak Memiliki Pengalaman Belajar Program TK dari Lima SD Se-Kec.Mata Oleo

\begin{tabular}{|c|c|c|c|c|c|}
\hline $\begin{array}{l}\text { No. } \\
\text { Urut }\end{array}$ & $\begin{array}{c}\text { No. } \\
\text { Urut Sampel }\end{array}$ & Nama Murid Kelas I & $\begin{array}{l}\text { Nilai } \\
\text { Prestasi }\end{array}$ & Nama SD & $\begin{array}{l}\text { Jenis } \\
\text { Kelamin }\end{array}$ \\
\hline 1 & 3 & Nurul Fadilatul & 60.30 & SDN 36 & $P$ \\
\hline 2 & 4 & Triani & 60.10 & SDN 36 & $P$ \\
\hline 3 & 5 & Nabil & 60.10 & SDN 36 & $\mathrm{~L}$ \\
\hline 4 & 6 & Isya Putri & 60.60 & SDN 36 & $P$ \\
\hline 5 & 7 & Ovin Pratama & 60.80 & SDN 36 & $\mathrm{~L}$ \\
\hline 6 & 8 & Irul & 60.10 & SDN 36 & $\mathrm{~L}$ \\
\hline 7 & 9 & Marvel & 60.30 & SDN 36 & $\mathrm{~L}$ \\
\hline 8 & 11 & St. Hadjar & 60.10 & SDN 36 & $P$ \\
\hline 9 & 12 & Muh. Bilal & 60.10 & SDN 36 & $\mathrm{~L}$ \\
\hline 10 & 15 & Stevan & 60.00 & SDN 36 & $\mathrm{~L}$ \\
\hline 11 & 16 & Marvin & 60.10 & SDN 36 & $\mathrm{~L}$ \\
\hline 12 & 17 & Alim & 60.10 & SDN 36 & $\mathrm{~L}$ \\
\hline 13 & 18 & Risky & 60.00 & SDN 36 & $P$ \\
\hline 14 & 19 & Anggriani & 50.90 & SDN 36 & $P$ \\
\hline 15 & 20 & Budi & 60.50 & SDN 36 & $\mathrm{~L}$ \\
\hline 16 & 21 & Muh. Ismah & 60.48 & SDN 36 & $\mathrm{~L}$ \\
\hline 17 & 22 & Monalisa & 68.80 & SDN 36 & $P$ \\
\hline 18 & 28 & Musdalifa & 60.00 & SDN 36 & $\mathrm{P}$ \\
\hline 19 & 29 & Melati. S & 60.62 & SDN 36 & $P$ \\
\hline 20 & 32 & Rahim & 60.30 & SDN 36 & $\mathrm{~L}$ \\
\hline 21 & 33 & Reyhan & 60.50 & SDN 36 & $\mathrm{~L}$ \\
\hline 22 & 35 & Sofyan & 60.45 & SDN 36 & $\mathrm{~L}$ \\
\hline 23 & 39 & Afisyahri & 60.05 & SDN 36 & $P$ \\
\hline 24 & 42 & Awal & 50.50 & SDN 39 & $\mathrm{~L}$ \\
\hline 25 & 43 & Buyung & 60.20 & SDN 39 & $\mathrm{~L}$ \\
\hline 26 & 44 & Boby & 50.80 & SDN 39 & $\mathrm{~L}$ \\
\hline 27 & 46 & Iwan & 50.60 & SDN 39 & $\mathrm{~L}$ \\
\hline 28 & 47 & Riswanto & 60.00 & SDN 39 & $\mathrm{~L}$ \\
\hline 29 & 51 & Julfikry & 50.70 & SDN 39 & $\mathrm{~L}$ \\
\hline 30 & 52 & Nurhidayat & 60.80 & SDN 39 & $\mathrm{~L}$ \\
\hline 31 & 54 & Bella & 60.10 & SDN 39 & $P$ \\
\hline 32 & 56 & Intan & 60.00 & SDN 39 & $\mathrm{P}$ \\
\hline 33 & 60 & Nirma & 50.90 & SDN 39 & $\mathrm{P}$ \\
\hline 34 & 61 & Arga & 50.30 & SDN 39 & $\mathrm{~L}$ \\
\hline 35 & 62 & Adam & 50.00 & SDN 39 & $\mathrm{~L}$ \\
\hline 36 & 63 & Fahril & 50.80 & SDN 39 & $\mathrm{~L}$ \\
\hline 37 & 64 & Riswanto & 50.05 & SDN 39 & $\mathrm{~L}$ \\
\hline 38 & 66 & Raju & 50.00 & SDN 39 & $\mathrm{~L}$ \\
\hline 39 & 70 & Amira & 60.10 & SDN 39 & $P$ \\
\hline
\end{tabular}




\begin{tabular}{|c|c|c|c|c|c|}
\hline 40 & 73 & Inang & 50.62 & SDN 39 & $\mathrm{P}$ \\
\hline 41 & 74 & Mawar & 50.60 & SDN 39 & $\mathrm{P}$ \\
\hline 42 & 75 & Cika & 50.30 & SDN 39 & $\mathrm{P}$ \\
\hline 43 & 76 & Alien & 50.05 & SDN 39 & $\mathrm{P}$ \\
\hline 44 & 77 & Rianti & 50.00 & SDN 39 & $\mathrm{P}$ \\
\hline 45 & 78 & Aditya & 50.03 & SDN 39 & $L$ \\
\hline 46 & 79 & Putri & 70.65 & SD Mawar & $\mathrm{P}$ \\
\hline 47 & 80 & Amel & 70.77 & SD Mawar & $P$ \\
\hline 48 & 81 & Fadly & 71.66 & SD Mawar & $\mathrm{L}$ \\
\hline 49 & 82 & Ikbal & 62,55 & SD Mawar & $L$ \\
\hline 50 & 83 & Kaimuddin & 61.11 & SD Mawar & $\mathrm{L}$ \\
\hline 51 & 84 & Levi & 62.88 & SD Mawar & $\mathrm{L}$ \\
\hline 52 & 85 & Syahid & 62.00 & SD Mawar & $\mathrm{L}$ \\
\hline 53 & 89 & Rachim & 70.88 & SD Mawar & $\mathrm{L}$ \\
\hline 54 & 90 & Delvin & 60.00 & SD Mawar & $\mathrm{L}$ \\
\hline 55 & 91 & Ayu & 60.33 & SD Mawar & $P$ \\
\hline 56 & 92 & Desti & 62.66 & SD Mawar & $P$ \\
\hline 57 & 95 & Viona & 60.00 & SD Mawar & $P$ \\
\hline 58 & 100 & Lisda & 55.50 & SDN 42 & $P$ \\
\hline 59 & 101 & Luna & 60.00 & SDN 42 & $P$ \\
\hline 60 & 102 & Ridho & 63.33 & SDN 42 & $\mathrm{~L}$ \\
\hline 61 & 106 & Widyawati & 55.00 & SDN 42 & $P$ \\
\hline 62 & 107 & Farel & 66.66 & SDN 42 & $\mathrm{~L}$ \\
\hline 63 & 109 & Arjun & 60.00 & SD B.Sampe & $\mathrm{L}$ \\
\hline 64 & 114 & Siti Juliani & 60.20 & SD B.Sampe & $P$ \\
\hline 65 & 116 & Hendra & 67.75 & SD B.Sampe & $\mathrm{L}$ \\
\hline 66 & 118 & Sulfikry & 69.85 & SD B.Sampe & $\mathrm{L}$ \\
\hline \multirow{2}{*}{\multicolumn{2}{|c|}{$\begin{array}{c}\text { ¿Murid Kelas I Unit } \\
\text { Kelompok } \\
\text { Sampel Populasi } \\
\text { bkn TK }\left(\mathrm{X}_{2}\right)=66\end{array}$}} & $\begin{array}{c}\sum \text { Total Nilai Murid Kelas I } \\
\left(\text { kelompok } X_{2}\right)\end{array}$ & 3886.53 & \multirow[b]{2}{*}{$\sum S D=5$} & $L=38$ \\
\hline & & $\begin{array}{c}\text { Rata-rata Nilai Murid Klas } \\
\text { I yg bkn dari TK } \\
\left(\text { kelompok } X_{2}\right)\end{array}$ & 58.59 & & $P=28$ \\
\hline
\end{tabular}

Tabel 4 Rekapitulasi Sebaran Data Nilai Prestasi Belajar secara Keseluruhan Sampel yang Tersebar pada 5 (lima) SD se-Kec. Mata Oleo Kab. Bombana, Tahun 2019

\begin{tabular}{|c|c|c|c|c|}
\hline No & $\begin{array}{c}\text { Se-Kecamatan Mata Oleo } \\
\text { Kab. Bombana }\end{array}$ & $\begin{array}{c}\sum \text { Total Murid } \\
\text { Kelas I }\end{array}$ & $\begin{array}{c}\sum\left(\mathrm{X}_{2}\right) \text { Murid } \\
\text { yang tidak } \\
\text { Program TK }\end{array}$ & $\begin{array}{c}\sum \text { Total Nilai } \\
\text { Prestasi Seluruh } \\
\text { Murid Kelas I }\end{array}$ \\
\hline 1 & SDN 36 Pulau Tambako & 39 & 23 & 2414.98 \\
\hline 2 & SDN 39 Pulau Tambako & 39 & 22 & 2245.15 \\
\hline 3 & SD Swasta 36 Mawar & 17 & 12 & 1139.13 \\
\hline 4 & SDN 42 Toli-Toli & 12 & 5 & 809.46 \\
\hline 5 & SDN Batu Sampe & 11 & 4 & 749.80 \\
\hline \multicolumn{2}{|c|}{ STotal (1+2+3+4+5) } & 118 & 66 & 7358.52 \\
\hline
\end{tabular}




\begin{tabular}{|c|}
\hline$(7358.52: 118) 62.36$ \\
\hline 80.66 \\
\hline 50.00 \\
\hline
\end{tabular}

Hasil Olahan Data Nilai Prestasi Murid, Tahun 2019

Berdasarkan hasil analisis statistik deskriptif terhadap data-data nilai prestasi belajar seluruh anggota kelompok sampel populasi murid kelas I yang tidak memiliki pengalaman belajar Program TK yang tersebar pada 5 (lima) SD yang terdapat di seKec.Mata Oleo Kab. Bombana, data-data yang ditampilan, menggambarkan sebaran jumlah sampel populasi murid SD kelas I yang tidak memiliki pengalaman belajar program TK beserta nilai prestasinya pada 5 SD se-Kec.Mata Oleo Kab. Bombana. Berikut ini, ringkasan data sampel murid yang tidak memiliki pengalaman belajar program TKyang tersebar pada 5 (lima) SD se-Kec.Mata Oleo Kab.Bombana, ditampilkan seperti nampak pada Tabel berikut:

Tabel 5 Rincian Deskriptif Sebaran Seluruh Anggota Kelompok Sampel yang Tidak Memiliki Pengalaman Belajar Program TKyang Tersebar pada 5 (Lima) Sekolah Dasar se-Kec. Mata Oleo Kab. Bombana, Tahun 2019

\begin{tabular}{|c|l|c|c|}
\hline No & $\begin{array}{c}\text { Nama Sekolah Dasar Tempat Sekolah } \\
\text { Murid Anggota Sampel Populasi } X_{2} \text { di } \\
\text { Kecamatan Mata Oleo Kab. Bombana }\end{array}$ & $\begin{array}{c}\text { Frekuensi } \\
\text { Murid pada } \\
\text { setiap SD }\end{array}$ & $\begin{array}{c}\text { Frekuensi } \\
\text { Relatif (\%) }\end{array}$ \\
\hline 1 & SDN 36 Pulau Tambako & 23 & 34.85 \\
\hline 2 & SDN 39 Pulau Tambako & 22 & 33.33 \\
\hline 3 & SD Swasta Mawar Mata Oleo & 12 & 18.18 \\
\hline 4 & SDN 42 Toli-Toli & 5 & 7.58 \\
\hline 5 & SDN Batu Sampe & 4 & 6.06 \\
\hline & $\sum$ Total $(1+2+3+4+5)$ & 66 & 100.00 \\
\hline
\end{tabular}

Hasil Olahan Data Nilai Prestasi Murid tahun 2019

Tampilan data yang nampak terlihat pada Tabel 5, mendekriptifkan bahwa murid klas I yang tidak memiliki pengalaman belajar program TK yang tersebar pada lima Sekolah Dasar (SD) se-Kecamatan Mata Oleo Kab. Bombana. Berdasarkan data pada Tabel 5 itu, ternyata terdapat sejumlah 66 murid kelas I yang tidak memiliki pengalaman belajar program TK, yang bersekolah pada 5 (lima) SD se-Kecamatan Mata Oleo. Secara frekuensi relatifnya, dari sejumlah 66 murid anggota kelompok sampel, berkisar 34.85\% ( 23 murid) berada atau bersekolah di SDN 36 Pulau Tambako; sejumlah berkisar 33.33\% (22 murid) berada/bersekolah di SDN 39 Pulau Tambako; sejumlah berkisar 18.18\% (12 murid) terdapat/bersekolah di SD Swasta Mawar Mata Oleo; sejumlah berkisar $7.58 \%$ atau sebanyak 5 murid berada atau bersekolah di SDN 42 Toli-Toli; dan yang berada atau bersekolah pada SDN Batu Sampe sejumlah berkisar $6.06 \%$ atau sebanyak 4 murid.

Berdasarkan kriteria kategorisasi yang digunakan sebagai acuan kriteria pada pengolahan data hasil penelitian ini untuk menentukan tingkat kategori prestasi belajar murid berdasarkan perolehan nilai hasil-hasil belajarnya, maka prestasi belajar tertinggi dengan nilai 71.66 merupakan tingkat prestasi yang berkategori "Baik", 
sedangkan prestasi belajar terendah dengan nilai 50,00 merupakan tingkat prestasi yang berkategori "Sangat Kurang Baik". Selengkapnya sebaran data nilai prestasi belajar murid kelas I yang tidak memiliki pengalaman belajar program TK di 5 (lima) SD se-Kec. Mata Oleo, ditampilkan pada halaman lampiran 7.B. Berdasarkan nilai prestasi belajarnya, dengan mengacu pada aturan kriteria dalam pengkategorisasian tingkat nilai prestasi belajar yang diterapkan, maka secara relatif dapat dideskripsikan keadaan nilai dan kategori tingkat prestasi belajar seluruh anggota sampel populasi murid kelas I yang tidak memiliki pengalaman belajar program TK pada 5 (lima) SD se-Kec.Mata Oleo Kab. Bombana, seperti yang ditampilkan pada Tabel berikut ini:

Tabel 6 Deskriptif Kategorisasi Tingkat Prestasi Belajar secara Keseluruhan Sampel yang Tidak Memiliki Pengalaman Belajar Program TK yang Tersebar/Bersekolah pada 5 (lima) SD di se-Kec. Mata Oleo Kab. Bombana, Tahun 2019.

\begin{tabular}{|c|c|c|r|}
\hline $\begin{array}{c}\text { Batasan Standar Interval } \\
\text { Kategori Nilai Tingkat } \\
\text { Prestasi }\end{array}$ & $\begin{array}{c}\text { Deskripsi Kategori } \\
\text { Tingkat Prestasi }\end{array}$ & $\begin{array}{r}\text { Frekuensi Murid } \\
\text { Sesuai } \\
\text { Kategori } \\
\text { Tingkat Prestasi }\end{array}$ & $\begin{array}{c}\text { Frekuensi } \\
\text { Relatif } \\
(\%)\end{array}$ \\
\hline $72.79 \leq$ & Sangat Baik & 0 & $0 \%$ \\
\hline $72.79-65.84$ & Baik & 8 & $12.12 \%$ \\
\hline $65.84-55.88$ & Cukup Baik & 39 & $59.09 \%$ \\
\hline $55.88-51.93$ & Kurang Baik & 2 & $3.03 \%$ \\
\hline$\leq 51.93$ & Sangat Kurang Baik & 17 & $25.76 \%$ \\
\hline & Jumlah Frekuensi & 66 & $100.00 \%$ \\
\hline
\end{tabular}

Sumber: Hasil Olahan Data Penelitian, Tahun 2019

Tampilan hasil olahan data penelitian mendeskripsikan keadaan tingkat prestasi belajar secara keseluruhan sampel populasi murid SD kelas I yang tidak memiliki pengalaman belajar Program TK yang tersebar pada 5 (lima) SD se-Kec.Mata Oleo Kab.Bombana, berdasarkan hasil evaluasi perolahan nilai prestasi hasil belajarnya pada masing-masing SD di akhir semesteran. Dari sejumlah 66 unit sampel populasi murid kelas I SD yang tidak memiliki pengalaman belajar Program TK, sebanyak berkisar 12.12\% atau 8 murid anggota Kelompok Sampel yang berhasil dengan capaian nilai tingkat prestasi belajar yang berkategori 'Baik'; sebanyak berkisar $59.09 \%$ atau 22 murid dari 66 murid kelompok Sampel yang berhasil dengan capaian nilai tingkat prestasi belajar yang berkategori 'Cukup Baik'; sebanyak berkisar 3.03\% atau 2 murid berhasil dengan capaian nilai tingkat prestasi belajar yang berkategori 'Kurang Baik'; dan berkisar 25.76\% atau 17 dari sejumlah 66 murid yang berkategori 'Sangat Kurang Baik'.

Tampilan data yang terlihat pada tabel 6 itu, menunjukkan pula bahwa dari sejumlah 66 murid SD kelas I yang tidak memiliki pengalaman belajar Program TK (Kelompok Sampel Populasi $\mathrm{X}_{2}$ ), tidak satupun menunjukkan nilai tingkat prestasi belajar yang berkategori 'Sangat Baik'. Dengan perkataan yang lain bahwa tidak satupun murid SD Kelas I yang tidak memiliki pengalaman belajar program TK yang tersebar atau bersekolah pada 5 (lima) SD di se-Kec. Mata Oleo Kab. Bombana 
tersebut, yang menunjukkan keberhasilan belajar dengan perolehan nilai tingkat prestasi belajar yang berkategori'Sangat Baik'.

\section{Pembahasan}

Berdasarkan hasil- hasil analisis seperti yang ditampilkan pada beberapa Tabel pada halaman sebelumnya, dapat diketahui suatu deskripsi kemampuan rata-rata dari keseluruhan murid kelas I yang terdapat pada 5 (lima) SD se-Kec.Mata Oleo Kab.Bombana berdasarkan perolehan nilai prestasi yang dicapainya. Kenyataan yang nampak dari hasil penelitian ini, diketahui bahwa sebagian besar atau berkisar $12,12 \%$ atau sejumlah 8 dari 66 jumlah murid SD kelas I di se-Kec. Mata Oleo Kab. Bombana, rata-rata memperoleh nilai prestasi belajar antara nilai 65,84-72,79 yang berkategori "Baik". Kemudian 39 murid di se-Kec. Mata Oleo Kab. Bombana tersebut, berkisar $59,09 \%$ jumlah murid SD kelas I yang memperoleh nilai prestasi belajar antara nilai 55,88-64,84 dengan kategori "Cukup Baik", dan 2 murid atau 03,03\% jumlah murid kelas 1 yang memperoleh nilai belajar antara nilai 51,93-55,88 memperoleh kategori "kurang Baik" serta . 17 murid atau 25,76\% jumlah murid kelas 1 yang memperoleh nilai belajar antara nilai 51,93 kebawah memperoleh kategori "Sangat kurang Baik" s

Kenyataan yang juga nampak dari tampilan data hasil di bagian hasil penelitian ini, yakni bahwa nilai rata-rata dari nilai capaian prestasi belajar seluruh murid kelas I yang terdapat di 5 (lima) SD se-Kec.Mata Oleo Kab.Bombana yakni berkisar mean = 62.63. Sehingga dengan mengacu pada nilai mean $=62,63$ ini, maka dapat diinterpresikan deskriptif keadaan rata-rata prestasi belajar dari kelompok sampel populasi murid yang memiliki pengalaman belajar program TK di kecamatan Mata Oleo kabupaten Bombana adalah Cukup baik. Temuan tersebut menguatkan pandangan (Pahendra et al., 2021) yang mengilustrasikan pentingnya pendidikan PAUD bagi anak karena melalui PAUD, anak dikembangkan keterampilan motorik kasar, halus dan aspek-aspek lainnya.

Melalui penggunaan acuan deviasi standar (SD) dan nilai rata-rata (mean) distribusi sebaran data-data nilai prestasi belajar dari sampel murid SD kelas I yang terdapat pada 5 (lima) SD di se-Kec. Mata Oleo Kab. Bombana secara keseluruhan, maka diperoleh suatu kategorisasi tingkat prestasi belajar dari perolehan nilai yang berhasil dicapai oleh masing-masing kelompok sampel populasi secara keseluruhan. Mencermati hasil-hasil analisis data-data nilai prestasi belajar perolehan murid kelas I SD se-Kec.Mata Oleo itu, maka secara deskriptif dapat diasumsikan bahwa secara umum nilai prestasi belajar yang dicapai oleh seluruh murid SD Kelas I dari kelompok sempel murid yang memiliki pengalaman belajar program TK perlu dikembangkan lebih lanjut.

\section{KESIMPULAN}

Berdasarkan hasil penelitian, diperoleh hasil bahwa secara rata-rata, tingkat prestasi murid Kelas I Sekolah Dasar Kecamatan Mataoleo yang memiliki pengalaman belajar di taman kanak kanak adalah 8 murid atau 12,12 \% berada pada tingkatan yang berkategori "Baik", kemudian 39 murid atau 59,09\% berada pada tingkatan berkategori "Cukup Baik", dan 2 murid atau 3.03 \% dengan kategori "Kurangt Baik". Serta 17 murid atau 25,76 berada pada kategori sangat tidak baik. Namun apabila 
mengambil capaian rata rata maka didapat nilai rata-rata $63,14 \%$ atau berada pada kategori"Cukup Baik". Dapat disimpulkan bahwa murid sekolah dasar yang tidak memiliki pengalaman belajar di taman kanak kanak mempunyai prestasi Cukup baik atau dibawa rata rata, oleh karena itu diharapkan anak sebelum masuk sekolah dasar harus memiliki pengalaman belajar di taman kanak kanak. Bagi orang tua, masyarakat dan pemerintah yang ada di kabupaten Bombana dan kecamatan Mataoleo pada khususnya untuk kiranya dapat lebih meningkatkan perannya dalam program PAUD, dan jika perlu berperan serta dalam upaya-upaya mendirikan kelompok-kelompok belajar bagi anak usia dini.

\section{UCAPAN TERIMAKASIH}

Artikel ini berhasil disusun karena kontribusi banyak pihak, untuk itu penulis mengucapkan banyak terima kasih kepada semua orang yang telah ikut berkontribusi. Ucapan terima kasih juga peneliti berikan kepada editor Journal of Education and Teaching (JET), Fakultas keguruan dan ilmu pendidikan, Universitas muhammadiyah kendari yang siap menyediakan media, dan telah memberikan saran, masukan, dan pelayanan untuk kesempurnaan tulisan ini.

\section{DAFTAR PUSTAKA}

Armstrong, (2011). The Best Schools: Mendidik Siswa Menjadi Insan Cendekia Seutuhnya. (Penerjemah Mursid Widjanarko) Bandung: Mizan Pustaka.

Conny, Semiawan. (2007). Belajar dan Pembelajaran dalam Taraf Usia Dini: Pendidikan Prasekolah dan Dasar. Jakarta: Prenhalindo.

Depdiknas. (2003). Panduan Strategi Mengajar Pendidikan TK. Jakarta: Bagpro Bina Penataran Guru TK/SD Setara D-III. Dirjen Dikdasmen.

Depdiknas. (2010). Kurikulum TK: Pedoman Pengembangan Program Pembelajaran dan Pengembangan Indikator Pencapaian Perkembangan Anak di TK/RA. Jakarta: Direktorat Bina TK dan Sekolah Dasar.

Depdiknas. (2012). Himpunan Perundang-Undangan Republik Indonesia tentang Sistem Pendidikan Nasional (SISDIKNAS); Dilengkapi Peraturan Perundangan yang Terkait. Jakarta: Penerbit Nuansa Mulia.

Dwihastuti. (2008). Investasi Pendidikan Bagi Anak Usia Dini Dalam Pembentukan Sumberdaya Manusia yang Berkualitas. Bulletin PADU Jurnal IImiah Anak Dini Usia. Edisi Khusus Tahun 2008. Jakarta: Dirjen PNFI-Direktorat PAUD

Fadillah. (2012). Desain Pembelajaran Pendidikan Anak Usia Dini (PAUD); Tinjauan Teoritik dan Praktik. Jogjakarta: Ar-Ruzz Media Pustaka Press.

Hamid, R. ., Hidayat, A. ., \& Safitri, A. . (2021). Pengaruh Penerapan Model Problem Based Learning (PBL) terhadap Prestasi Belajar Siswa . Jurnal Ilmu Manajemen Sosial Humaniora (JIMSH), 3(1), 1-9. https://doi.org/10.51454/jimsh.v3i1.52

Hibama, S. Rahman. (2009). Strategi dan Konsep Dasar Pendidikan Anak Usia Dini. Yogyakarta: PGTKI Press.

Haryati, Mimin. (2010). Model dan Teknik Penilaian Pada Tingkat Satuan Pendidikan. Jakarta: Gaung Persada Press.

Heruman. (2012). Model Pembelajaran di Sekolah Dasar. Bandung: Penerbit PT. Remaja Rosda Karya. 
Hudoyo. (2004). Strategi Belajar Mengajar. Jakarta: P2LPTK, Direktorat Pendidikan Tinggi. Depdikbud

Kamarga, Hansiswani. (2007). Implementasi Kurikulum Tematik: Jurnal Himpunan Pengembang Kurikulum Indonesia (HIPKIN). Tahun 2, Vol.1 Nomor 1 Periode September. Bandung: Penerbit HIPKIN UPI press

Latipah. (2012). Pengantar Psikologi Pendidikan. Yogyakarta: Pustaka Insan Madani.

Nurdin. (2010). Perbandingan Prestasi Belajar Siswa Kelas I yang Melalui PAUD dengan Murid Yang tidak Melalui PAUD di SD Negeri 1 Lambolemo, Kecamatan Samaturu, Kabupaten Kolaka". Skripsi. Tidak Dipublikasikan. Kendari: Perpustakaan Universitas Muhammadiyah Kendari.

Pahenra, P. (2021). Optimalisasi Guru dalam Membuat Media Pembelajaran untuk Mestimulasi Kemampuan Kognitif Anak Usia Dini. Journal of Education and Teaching (JET), 1(2), 67-74. https://doi.org/10.51454/jet.v1i2.16

Pahendra, Selman, H., Rohmiati, Said, H., Sasnita, U., Nasir, \& Indah, T. (2021). Sirkuit Bola Keranjang: Permainan untuk Meningkatkan Kemampuan Motorik Kasar Anak Usia Dini. Obsesi, 5(2), 2025-2036. https://doi.org/10.31004/obsesi.v5i2.1077

Prasetyo, Bambang. (2011). Metodologi Penelitian Kuantitatif. Jakarta: Rajawali Press. Rachmawati, Yeni \& Euis Kurniati. (2005). Strategi Pengembangan Kreativitas Pada Anak Usia Taman Kanak-Kanak. Jakarta: Direktorat P2TKKPT, Dirjen Dikti.

Reksoatmodjo. (2009). Pengantar Statistika Untuk Psikologi dan Pendidikan. Bandung: Penerbit Refika Aditama Grafindo.

Riduwan, 2011. Dasar-Dasar Statistika. Bandung: AlfaBeta.

Ruseffendi. (2004). Pengantar Strategi CBSA Untuk Membantu Guru Mengembangkan Kompetensinya dalam Pengajaran. Bandung: Tarsito.

Subagyo. (2011). Statistika Terapan. Yogyakarta: Fekon dan Bisnis UGM Press.

Sudijono. (2010). Pengantar Statistik Pendidikan. Jakarta: PT. Raja Grafindo Persada.

Sudjana. (2002). Dasar-Dasar Metode Statistika, (Jilid 6). Bandung: Tarsito.

Sudono, Anggani. (2010). Sumber Belajar dan Alat Permainan untuk Pendidikan Anak Usia Dini; (Edisi Revisi). Jakarta: Penerbit PT. Grasindo

Sugiyono. (2009). Metode Penelitian Pendidikan (Suatu Pendekatan Kuatitatif, Kualitatif dan R\&D). Bandung: Alfabeta.

Sukmadinata. (2012). Metodologi Penelitian Pendidikan: Suatu Pengantar Teoritik dan Praktik. Bandung: Remaja Rosdakarya.

Susanto. (2001). Strategi Pembelajaran Aktif, Inovatif dan Partisipatif. Jakarta: Direktorat Ketenagaan, Direktorat Jendral Pendidikan Tinggi; Depdiknas.

Trisnawati. (2011). “Perbedaan Kemampuan Sosial Antara Yang Perna Mengikuti TK dan Yang Tidak Perna Mengikuti TK pada Murid Kelas IB SD Negeri 06 Kendari. (Skripsi). Tidak Dipublikasikan. Kendari: Perpustakaan Universitas Muhammadiyah Kendari.

Yuliani. (2005). Metode Pengembangan Kognitif. Buku Materi Pokok PGTK, Modul 112. Jakarta: Penerbit Lembaga Penerbitan UT. 